\title{
Lewis versus Brønsted Acid Activation of a Mn(IV) Catalyst for Alkene Oxidation
}

\author{
Jorn D. Steen, ${ }^{\dagger}$ Stepan Stepanovic, ${ }^{\dagger} \triangle$ Mahsa Parvizian, $^{\dagger}$ Johannes W. de Boer, ${ }^{\S}$ Ronald Hage, ${ }^{\dagger, \S}$

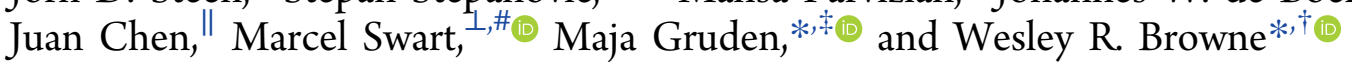 \\ ${ }^{\dagger}$ Molecular Inorganic Chemistry, Stratingh Institute for Chemistry, Faculty of Science and Engineering, University of Groningen, \\ Nijenborgh 4, 9747 AG, Groningen, The Netherlands \\ ${ }^{\ddagger}$ Faculty of Chemistry, University of Belgrade, Studentski trg 12-16, 11000 Belgrade, Serbia \\ ${ }^{\S}$ Catexel B.V., BioPartner Center Leiden, Galileiweg 8, 2333 BD Leiden, The Netherlands \\ "Department of Applied Chemistry, School of Science, Northwestern Polytechnical University, Xi'an, Shaanxi 710072, China \\ ${ }^{\perp}$ IQCC \& Departament de Química, Universitat de Girona, Campus Montilivi (Ciències), 17003 Girona, Spain \\ \#ICREA, Pg. Lluís Companys 23, 08010 Barcelona, Spain
}

Supporting Information

ABSTRACT: Lewis acid (LA) activation by coordination to metal oxido species has emerged as a new strategy in catalytic oxidations. Despite the many reports of enhancement of performance in oxidation catalysis, direct evidence for LA-catalyst interactions under catalytically relevant conditions is lacking. Here, we show, using the oxidation of alkenes with $\mathrm{H}_{2} \mathrm{O}_{2}$ and the catalyst $\left[\mathrm{Mn}_{2}(\mu-\mathrm{O})_{3}(\text { tmtacn })_{2}\right]\left(\mathrm{PF}_{6}\right)_{2}(1)$, that Lewis acids commonly used to enhance catalytic activity, e.g., $\mathrm{Sc}(\mathrm{OTf})_{3}$, in fact undergo hydrolysis with adventitious water to release a strong Brønsted acid. The formation of Brønsted acids in situ is demonstrated using a combination of resonance Raman, UV/vis absorption spectroscopy, cyclic voltammetry, isotope labeling, and DFT calculations. The involvement of Brønsted acids in LA enhanced systems shown here holds implications for

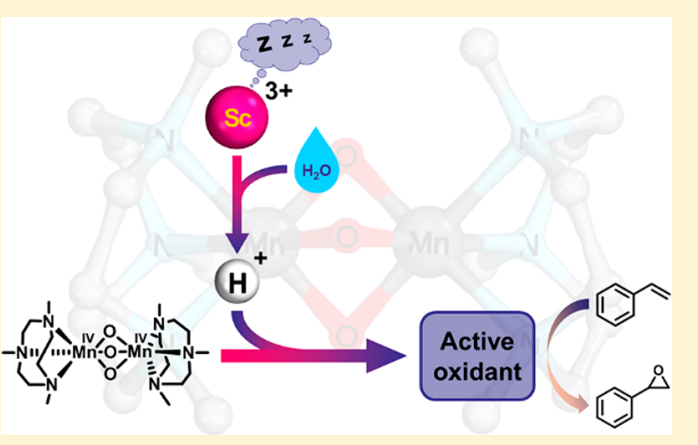
the conclusions reached in regard to the relevance of direct LA-metal oxido interactions under catalytic conditions.

\section{INTRODUCTION}

The interaction of Lewis acids (LAs) with transition metal complexes and clusters can profoundly change their reactivity, which is most clearly manifested in the critical role of calcium ions in the oxygen evolving complex of photosystem (PS) II. ${ }^{1,2}$ Recent reports have highlighted correlations between Lewis acidity and properties of transition metal complexes, such as redox potential, ${ }^{3-5}$ and by extrapolation the enhancements in activity that they bring in oxidation catalysis, e.g., using iron $^{6-15}$ and manganese complexes. ${ }^{16-29}$ However, the causal nature of the effects of LAs and indeed the actual interactions between them and transition metal complexes under catalytic conditions are unclear. In particular, their binding to reactive species, although postulated, has not been confirmed in solution.

For example, Watkinson and Nodzewska ${ }^{30}$ and the group of $\mathrm{Yin}^{31}$ have described the exceptional impact of Lewis acids on the oxidation of alkenes with $\mathrm{H}_{2} \mathrm{O}_{2}$ catalyzed by the complex $\left[\mathrm{Mn}_{2}(\mu-\mathrm{O})_{3}(\operatorname{tmtacn})_{2}\right]\left(\mathrm{PF}_{6}\right)_{2}\left(1\right.$, where tmtacn is $N, N^{\prime}, N^{\prime \prime}-$ trimethyl-1,4,7-triazacyclononane, Scheme 1). The catalytic activity of $\mathbf{1}$ is dependent on the presence of Lewis acidic metal triflates such as $\mathrm{Sc}(\mathrm{OTf})_{3}$; alkene oxidation is not observed under the same conditions without a Lewis acid. This dependence was ascribed to binding of the Lewis acid to either $\mathbf{1}$ or the reactive intermediate responsible for substrate oxidation. Direct interaction between, e.g., $\mathrm{Sc}^{3+}$, and $\mathbf{1}$, was inferred from spectroscopic data and by analogy with known M-O-LA structures obtained in the solid state. ${ }^{32-34}$ Definitive evidence for such binding in solution is not available, however, especially under reaction conditions with, e.g., $\mathrm{H}_{2} \mathrm{O}_{2}$, where water is added with the oxidant in excess.

In the present contribution we show through a combination of spectroscopy and DFT calculations that the changes that follow addition of Lewis acids to $\mathbf{1}$ are not due to LA binding to an oxido unit of $\mathbf{1}$, as proposed for related $\mathrm{Fe}^{\mathrm{IV}}=\mathrm{O}$ complexes. $^{32-34}$ Instead, the effects observed are due to the release of a strong Brønsted acid upon hydrolysis of the metal triflates by adventitious water either present in the solvent or as water of crystallization in $\mathbf{1}$. The released Brønsted acid facilitates reduction of 1 by $\mathrm{H}_{2} \mathrm{O}_{2}$, and subsequent ligand exchange and redox reactions ${ }^{35}$ provide for the observed increase in catalytic performance.

Received: September 13, 2019

Published: October 18, 2019 
Scheme 1. Oxidation of Alkenes with $\mathrm{H}_{2} \mathrm{O}_{2}$ Catalyzed by $\left[\mathrm{Mn}_{2}(\mu-\mathrm{O})_{3}(\text { tmtacn })_{2}\right]^{2+}(1)$ and Proposed Roles of Lewis Acids

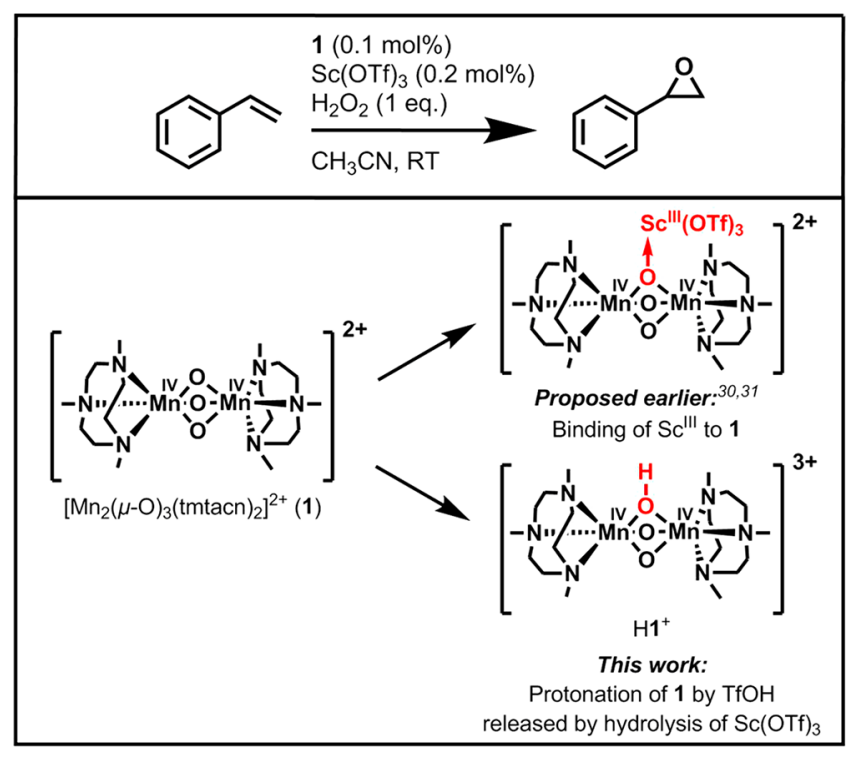

\section{RESULTS AND DISCUSSION}

As reported by Watkinson and Nodzewska and the group of Yin, we find here that the addition of metal triflates to 1 prior to the addition of $\mathrm{H}_{2} \mathrm{O}_{2}$ results in conversion of styrene to styrene oxide, albeit still with a substantial loss of $\mathrm{H}_{2} \mathrm{O}_{2}$ through disproportionation (Scheme 2 and Figures $\mathrm{S} 1$ and

Scheme 2. Key Stages in the Oxidation of Styrene (Blue) Catalyzed by $1(1 \mathrm{mM})$ with $\mathrm{Sc}(\mathrm{OTf})_{3}(2 \mathrm{mM})$ Using $\mathrm{H}_{2} \mathrm{O}_{2}$ (Magenta) As Oxidant ${ }^{a}$

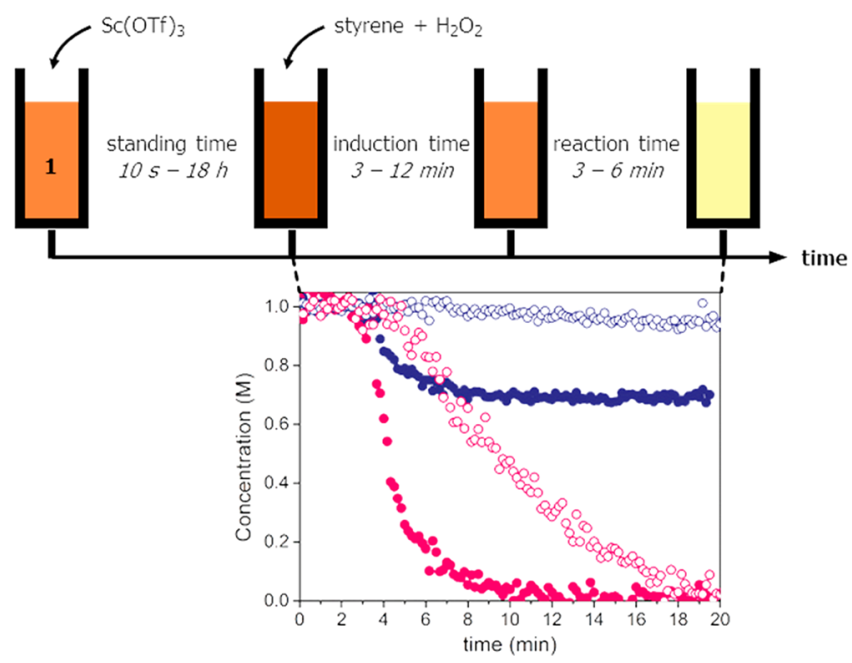

${ }^{a}$ Different standing times were used: $20 \mathrm{~s}$ (empty); $60 \mathrm{~min}$ (filled).

S2). The turnover numbers (TONs) achieved here in the presence of LAs, ca. 250, are consistent with the earlier reports (ca. 100)..$^{30,31}$ In-line monitoring of the oxidation of styrene reveals that, in the presence of Lewis acids, the reaction proceeds through two distinct phases (Scheme 2, Figure S2). The addition of $\mathrm{H}_{2} \mathrm{O}_{2}$ is followed by an induction period, after which both alkene oxidation and disproportionation of the $\mathrm{H}_{2} \mathrm{O}_{2}$ begin concomitantly. The duration of the induction period and the ratio of styrene conversion to $\mathrm{H}_{2} \mathrm{O}_{2}$ disproportionation depends on the time, here referred to as standing time, between the addition of the Lewis acid to $\mathbf{1}$ in anhydrous acetonitrile and the subsequent addition of styrene and $\mathrm{H}_{2} \mathrm{O}_{2}$ (Scheme 2). Disproportionation of $\mathrm{H}_{2} \mathrm{O}_{2}$ is observed regardless of the standing time, whereas conversion of styrene is observed only when the standing time exceeds several minutes. During the reaction, a white precipitate forms that is a mixture of insoluble manganese and scandium salts (by ICP, see Experimental Section for details) of, most likely, acetate formed by hydrolysis of acetonitrile. ${ }^{36,37}$ Although the addition of a second equivalent of $\mathrm{H}_{2} \mathrm{O}_{2}$ results in continued oxidation of styrene (Figure S3), the isolated precipitate is not catalytically active.

Other Lewis acids ${ }^{31}$ have similar effects to that of $\mathrm{Sc}(\mathrm{OTf})_{3}$, in terms of induction period and rate of oxidation. With $\mathrm{Al}(\mathrm{OTf})_{3}$ consistently higher, conversion of styrene was obtained, whereas with $\mathrm{Y}(\mathrm{OTf})_{3}$, the decomposition of $\mathrm{H}_{2} \mathrm{O}_{2}$ was slow, and negligible conversion of styrene was observed (Figure S2). Notably, however, with $\mathrm{Y}\left(\mathrm{CF}_{3} \mathrm{CO}_{2}\right)_{3}$, both rapid decomposition of $\mathrm{H}_{2} \mathrm{O}_{2}$ and significant conversion of styrene were observed. The relative performance of the Lewis acids correlates with their relative rates of hydrolysis; ${ }^{38}$ however, the counterion plays a role in the outcome of the reaction also. These data prompted us to examine the interaction between the LAs, and especially $\mathrm{Sc}(\mathrm{OTf})_{3}$, and $\mathbf{1}$.

Effect of Lewis Acids on the Electronic and Vibrational Spectroscopy of 1. The UV/vis absorption spectrum of 1 in acetonitrile shows a broad visible absorption at $490 \mathrm{~nm}$ and several more intense bands below $400 \mathrm{~nm} .^{39,40}$ The addition of 2 equiv of $\mathrm{Sc}(\mathrm{OTf})_{3}$ results in an increase in absorbance over the range 400 and $650 \mathrm{~nm}$ and the appearance of weak bands at ca. 750 and $850 \mathrm{~nm}$ (Figure 1a). The relative rate of change in absorbance is constant across the entire spectrum, indicative of a single step process. Notably, the changes are not immediate but take $>30$ s. The Raman spectrum at $\lambda_{\text {exc }} 355 \mathrm{~nm}$ undergoes concomitant changes with the resonantly enhanced $\mathrm{Mn}-\mathrm{O}-\mathrm{Mn}$ symmetric stretching band ${ }^{40,41}$ at $699 \mathrm{~cm}^{-1}$ decreasing in intensity and a band at 687 $\mathrm{cm}^{-1}$ appearing together with an increase in intensity of the band at $799 \mathrm{~cm}^{-1}$ (Figure 1b). DFT calculations and ${ }^{18} \mathrm{O}$ labeling indicate that the band at $699 \mathrm{~cm}^{-1}$ is a vibrational mode of the $\mathrm{Mn}-(\mu-\mathrm{O})_{3}-\mathrm{Mn}$ core, while the band at 799 $\mathrm{cm}^{-1}$ involves mostly the $\mathrm{Mn}-\mathrm{N}$ bonds, with little displacement of the $\mathrm{Mn}-(\mu-\mathrm{O})_{3}-\mathrm{Mn}$ core (Figure S4). Similar changes are observed at $\lambda_{\text {exc }} 457 \mathrm{~nm}$ (Figure S5). Weaker bands appear also that correspond to modes of the tmtacn ligand observed under nonresonant conditions $\left(\lambda_{\text {exc }} 785 \mathrm{~nm}\right.$, Figure S6). The addition of $\mathrm{Al}(\mathrm{OTf})_{3}$ resulted in identical changes to the $\mathrm{UV} /$ vis absorption and resonance Raman spectra of 1 , whereas the addition of $\mathrm{Y}(\mathrm{OTf})_{3}$ and $\mathrm{Y}\left(\mathrm{CF}_{3} \mathrm{CO}_{2}\right)_{3}$ did not (Figure $\mathrm{S} 7$ ).

The changes in the UV/vis absorption spectrum are similar to those reported by Lv et al., ${ }^{31}$ who proposed the formation of a mononuclear manganese(IV) complex analogous to that reported earlier by Chin Quee-Smith et al. (i.e., $\left[\mathrm{Mn}^{\mathrm{IV}}(\right.$ tmtacn $\left.\left.)(\mathrm{OMe})_{3}\right]\left(\mathrm{PF}_{6}\right)\right){ }^{42}$ However, the final UV/vis absorption spectrum is identical to that reported earlier by Hage et al. for 1 in concentrated $\mathrm{H}_{2} \mathrm{SO}_{4}{ }^{40}$ The addition of excess water after the addition of $\mathrm{Sc}(\mathrm{OTf})_{3}$ resulted in an immediate recovery of the initial $\mathrm{UV} /$ vis absorption and resonance Raman spectra of $\mathbf{1}$ (Figure 1), and indeed even 0.2 vol \% of water is sufficient for full recovery (see Figures S8a 

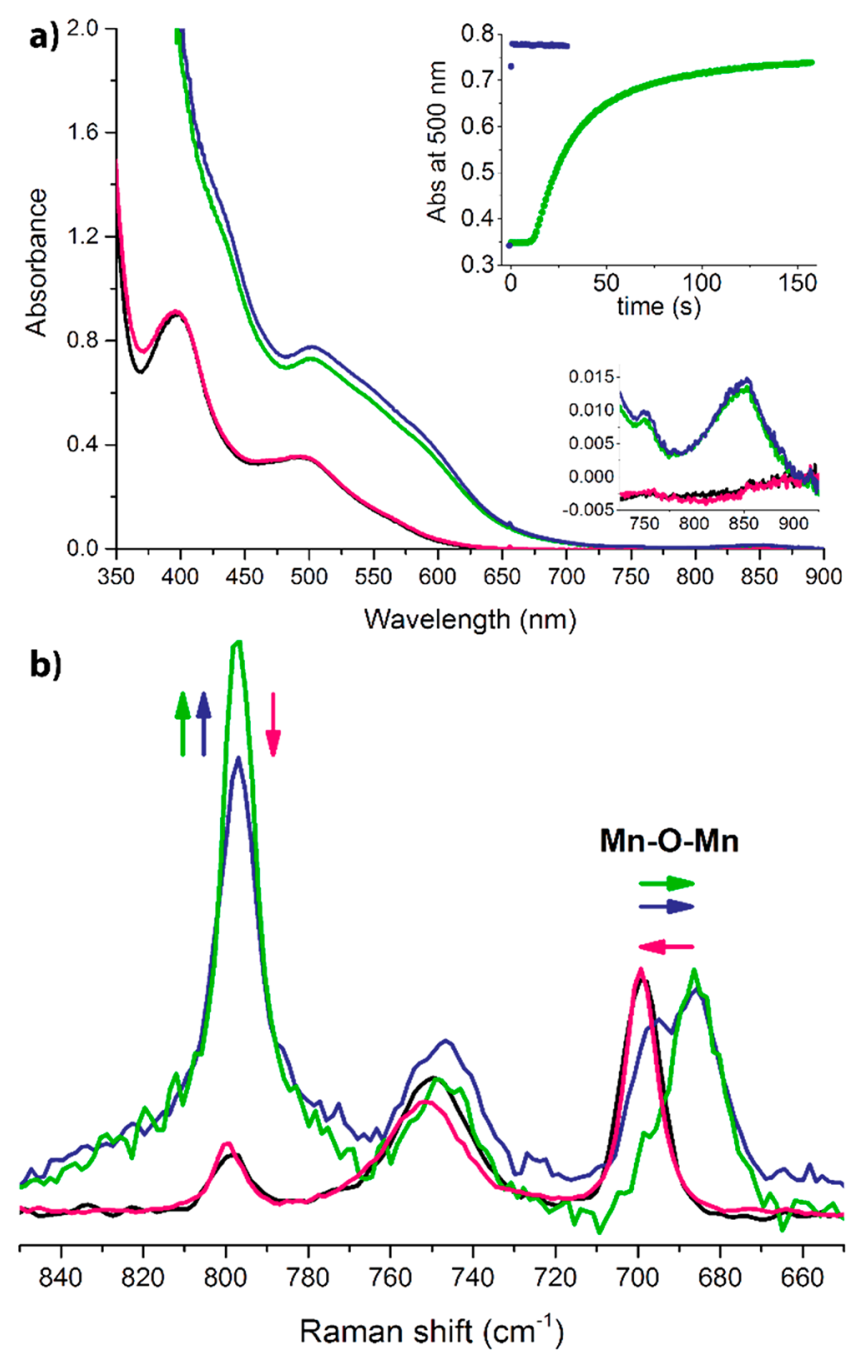

Figure 1. (a) $\mathrm{UV} /$ vis absorption spectroscopy of 1 in $\mathrm{CH}_{3} \mathrm{CN}$ before (black), after the addition of $\mathrm{Sc}(\mathrm{OTf})_{3}$ (2 equiv; green) or $\mathrm{TfOH}(6$ eq.; blue), and after subsequent addition of excess $\mathrm{H}_{2} \mathrm{O}$ (292 equiv; magenta), inset: absorbance at $500 \mathrm{~nm}$ over time after the addition of $\mathrm{Sc}(\mathrm{OTf})_{3}$ (2 equiv; green) or TfOH (6 equiv; blue). (b) Raman spectra $\left(\lambda_{\text {exc }} 355 \mathrm{~nm}\right)$ of 1 in $\mathrm{CH}_{3} \mathrm{CN}$ before (black), after the addition of $\mathrm{Sc}(\mathrm{OTf})_{3}$ (2 equiv; green) or TfOH ( 6 equiv; blue), and after subsequent addition of excess $\mathrm{H}_{2} \mathrm{O}$ (6200 equiv; magenta). See Figures S4 and S6 for measured and calculated shifts.

and $\mathrm{S} 8 \mathrm{~b})$. Furthermore, using $\mathrm{H}_{2}{ }^{18} \mathrm{O}$ did not result in incorporation of ${ }^{18} \mathrm{O}$ into $\mathbf{1}$ (by Raman spectroscopy, Figures S4 and S8c). ${ }^{40,43}$ Hence, the changes upon the addition of $\mathrm{Sc}(\mathrm{OTf})_{3}$ are unlikely to be due to "opening" of the $\mathrm{Mn}-\mathrm{O}-$ Mn bridges. ${ }^{35}$ Furthermore, DFT calculations indicate that although the formation of a $\mathrm{Sc}$ thermodynamically feasible, the calculated frequencies of the relevant vibrational mode (symmetric) do not match the shifts observed experimentally by Raman spectroscopy (Figure S9). In contrast the shifts calculated for $\mathbf{1}$ and $\mathrm{H}^{+}$match well (Figure S4). These data indicate that, in solution, Lewis acidic metal ions (e.g., $\mathrm{Sc}^{3+}$ ) do not bind to a bridging oxygen of $\mathbf{1}$, but instead $\mathbf{1}$ is protonated by Brønsted acids, vide infra.

Effect of Lewis Acids on the Cyclic Voltammetry of 1. A key role of Brønsted acids in activating $\mathbf{1}$ in catalytic oxidations is to shift its reduction potential to more positive potentials. This shift facilitates reduction of $\mathbf{1}$ by $\mathrm{H}_{2} \mathrm{O}_{2}$ from a $\mathrm{Mn}^{\mathrm{IV}}{ }_{2}$ state to dinuclear $\mathrm{Mn}^{\mathrm{II}}$ and $\mathrm{Mn}^{\mathrm{III}}$ species. ${ }^{41}$ These latter species are catalytically active as established earlier where $\mathbf{1}$ was used in the presence of carboxylic acids. ${ }^{35}$

DFT calculations indicate that binding of $\mathrm{Sc}^{3+}$ to the $\mathrm{Mn}-$ $(\mu-\mathrm{O})_{3}-\mathrm{Mn}$ core is thermodynamically favorable and changes the $\mathrm{Mn}-\mathrm{O}$ bond lengths substantially (see SI). The Sc-O bond is predicted to have a significant covalent bond character, close to that of the $\mathrm{O}-\mathrm{H}$ bond in $\mathrm{H1}^{+}$. Hence, notwithstanding the discussion above, binding of $\mathrm{Sc}(\mathrm{OTf})_{3}$ could shift the reduction potential of $\mathbf{1}$ in a similar manner to that induced by protonation and thereby facilitate reduction by $\mathrm{H}_{2} \mathrm{O}_{2}$. Indeed, cyclic voltammetry shows that the reduction of $\mathbf{1}$ at $-0.6 \mathrm{~V}$ vs $\mathrm{SCE}^{40}$ moves to ca. $0.4 \mathrm{~V}$ upon the addition of $\mathrm{Sc}(\mathrm{OTf})_{3}$ (Figure 2). The increase in current indicates a multielectron

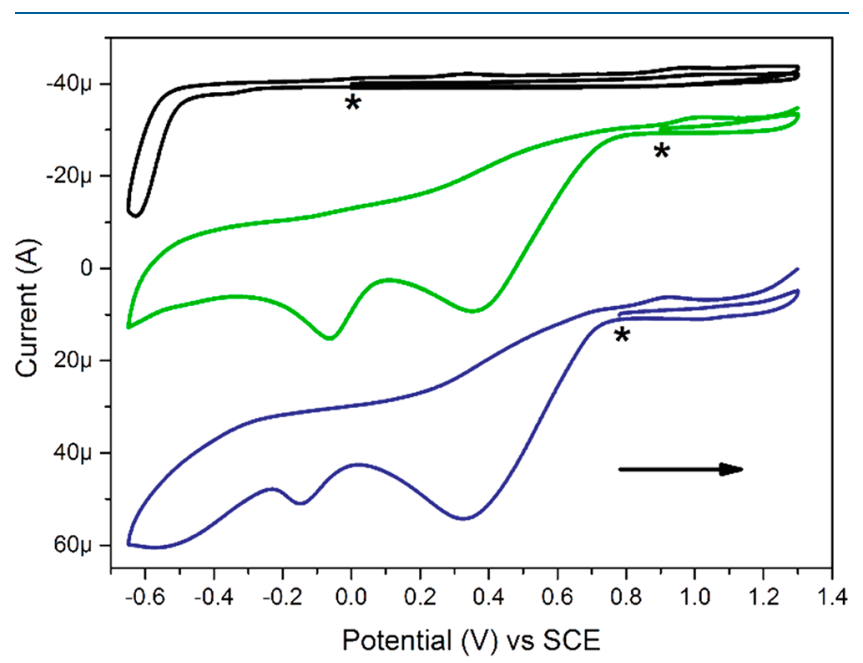

Figure 2. Comparison of the cyclic voltammetry of 1 (black) with that obtained after the addition of either $\mathrm{Sc}(\mathrm{OTf})_{3}$ (3 equiv; green) or $\mathrm{TfOH}$ (9 equiv; blue) in $0.1 \mathrm{M} \mathrm{TBAPF}_{6}$ in $\mathrm{CH}_{3} \mathrm{CN}$. Current axis offset for clarity. Initial potential and scan direction indicated by $*$ and black arrows, respectively.

process, and new oxidation waves at ca. $1.0 \mathrm{~V}$ on the return cycles are consistent with the formation of new species as shown earlier by de Boer et al. ${ }^{35}$

Notably these changes are almost identical to those observed upon the addition of $\mathrm{TfOH}$ to $\mathbf{1}$ (Figure 2). As with Lewis acids, the addition of water results in only a minor shift of the redox waves back toward negative potentials, and essentially the same general shape of the redox wave is observed (Figure S10), despite that $\mathrm{H}^{+}$reverts to 1 . It should be noted that even weak acids that are not able to fully protonate $\mathbf{1}$ can provide sufficient acidity to enable reduction due to the fast equilibriums involved (Figure S11). ${ }^{35}$ After standing for several minutes, additional redox waves at $0.6 \mathrm{~V}$ are observed with both $\mathrm{TfOH}$ and $\mathrm{Sc}(\mathrm{OTf})_{3}$ (Figures $\mathrm{S} 12$ and S13). ${ }^{35,40}$ The new redox waves at 0.65 and $1.05 \mathrm{~V}$ that appear over time in the presence of $\mathrm{Sc}(\mathrm{OTf})_{3}$ and of $\mathrm{TfOH}$ correspond to those of $\left[\mathrm{Mn}_{2}{ }_{2}(\mu-\mathrm{O})(\mu \text {-OAc })_{2}(\text { tmtacn })_{2}\right]^{2+}$ in the presence of acid (Figure S14). ${ }^{35}$

Comparison of the Lewis and Brønsted Acids on the Spectroscopy of 1 and Its Catalytic Activity. As for the cyclic voltammetry, $\mathrm{Sc}(\mathrm{OTf})_{3}$ and $\mathrm{TfOH}$ have essentially identical effects on the $\mathrm{UV} /$ vis absorption and resonance Raman spectra of $\mathbf{1}$ (Figure 1). Indeed, these same spectroscopic changes are observed upon the addition of concentrated $\mathrm{H}_{2} \mathrm{SO}_{4}$ (or $\mathrm{D}_{2} \mathrm{SO}_{4}$, Figure $\mathrm{S} 15$ ) to $\mathbf{1}$ in acetonitrile, and the changes are consistent with formation of 
the monoprotonated complex $\mathrm{Hi}^{+} .^{40,44}$ Notably the changes induced by Brønsted acids are instantaneous, in contrast to the gradual changes $(>30 \mathrm{~s})$ observed upon the addition of $\mathrm{Sc}(\mathrm{OTf})_{3}$. This difference is consistent with release of Brønsted acids by hydrolysis of $\mathrm{Sc}(\mathrm{OTf})_{3}{ }^{38,45}$ prior to protonation of 1 . It should be noted that 1 supplies 1 equivalent of water as water of crystallization, in addition to residual water already present in acetonitrile.

Having confirmed the spectroscopic similarities between the addition of $\mathrm{TfOH}$ and $\mathrm{Sc}(\mathrm{OTf})_{3}$ to 1 , the Brønsted acid assisted oxidation ${ }^{18,28,46}$ of styrene was examined. Essentially identical catalytic behavior was observed when using $\mathrm{TfOH}$ or $\mathrm{Sc}(\mathrm{OTf})_{3}$, including a lag period followed by rapid onset of $\mathrm{H}_{2} \mathrm{O}_{2}$ decomposition and oxidation of styrene (Figure 3).

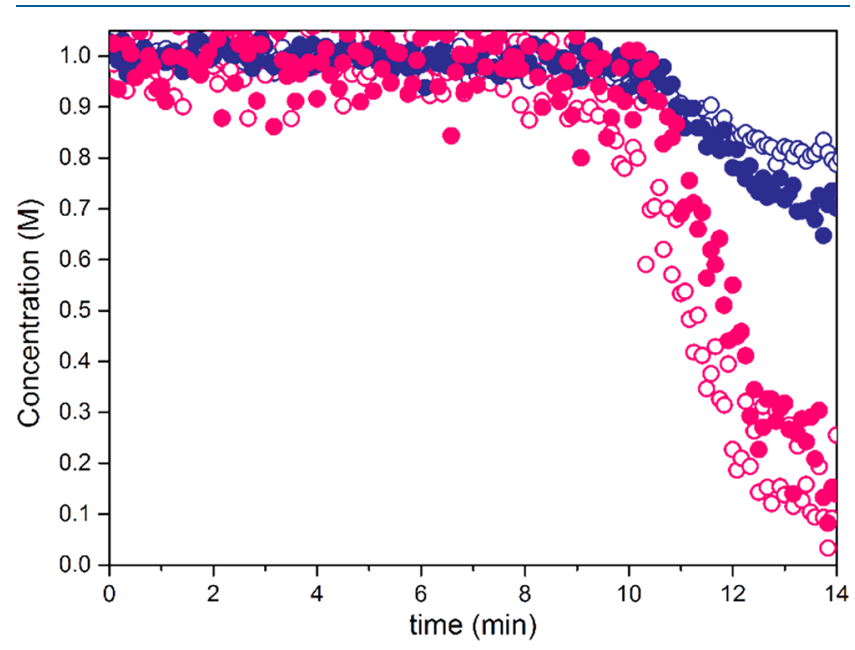

Figure 3. Comparison of kinetics of styrene conversion (blue) and $\mathrm{H}_{2} \mathrm{O}_{2}$ consumption (magenta) by $\mathbf{1}$ activated by either TfOH (6 equiv; filled) or $\mathrm{Sc}(\mathrm{OTf})_{3}$ (2 equiv; empty) for a $1 \mathrm{~h}$ standing time. In the absence of any acid, only disproportionation of $\mathrm{H}_{2} \mathrm{O}_{2}$ to $\mathrm{O}_{2}$ is observed (Figure S1).

Similar trends were observed with trifluoroacetic acid (Figure S16), reinforcing that triflic acid is not unique and other Brønsted acids are capable of activating 1 in the same way, i.e., by protonation assisted reduction from the $\mathrm{Mn}^{\mathrm{IV}, \mathrm{IV}}{ }_{2}$ state. ${ }^{47}$

The release of Brønsted acids from metal triflates in ostensibly anhydrous solvents has been noted in the literature under various conditions. For example in chlorinated solvents, Hintermann et al. reported that the reaction of AgOTf with a chlorinated substrate, and subsequently solvent, releases $\mathrm{TfOH}^{48}$ and recently, Schlegel et al. reported the release of catalytically active triflic acid in the metal triflate catalyzed glycosylation reactions. ${ }^{49}$ Gunnoe et al. have proposed the in situ generation of triflic acid from $\mathrm{Al}(\mathrm{OTf})_{3}$ in the hydroamination of nonactivated alkenylamines in solvents such as DMSO and nitrobenzene etc. ${ }^{50}$

In situ formation of $\mathrm{TfOH}$, specifically in acetonitrile, has been proposed by Dumeunier and Markó in the acylation of alcohols catalyzed by metal triflates, which serve as reservoirs of the Brønsted acid. ${ }^{51}$ Spencer et al. have identified Brønsted acids as the active catalysts in hetero-Michael additions to $\alpha, \beta$ unsaturated ketones in the presence of various metal salts ${ }^{52}$ and related the catalytic ability of a metal salt to the extent of hydrolysis-conversion was not observed with metal salts that do not undergo hydrolysis. Additionally, water (more than 2 equiv vs metal catalyst) retards the reaction due to its Brønsted basicity. The water in that case most likely originates from side reactions such as imine condensation and acetal/thioacetal formation, which are unavoidable under the nonbasic conditions used for the hetero-Michael addition.

In the present report, 1 equiv of water is present by default due to the fact that $\mathbf{1}$ is a monohydrate, but as discussed by Spencer et al. even if this is not the case water can form due to background reactions. Indeed, even when anhydrous, the water content is at a minimum 0.001-0.005 vol \%, which corresponds to approximately $0.5-3 \mathrm{mM}$ of $\mathrm{H}_{2} \mathrm{O}$. This is in the same concentration range as the manganese complex (1 $\mathrm{mM})$ and metal triflates $(2 \mathrm{mM})$. Furthermore, in addition to water added with the oxidant $\mathrm{H}_{2} \mathrm{O}_{2}$, even when in 90 wt \% concentration, the disproportionation of $\mathrm{H}_{2} \mathrm{O}_{2}$ generates $\mathrm{H}_{2} \mathrm{O}$ and $\mathrm{O}_{2}$, and during epoxidation 1 equiv of $\mathrm{H}_{2} \mathrm{O}$ is released also.

The $\mathrm{p} K_{\mathrm{a}}$ of $\mathbf{1}$ is lower than most strong acids and hence the leveling effect of water means that when present in excess of the $\mathrm{TfOH}$ formed, the strongest acid present is the hydronium ion, which is unable to protonate $\mathbf{1}$ to an extent detectable by spectroscopic methods. Neither yttrium(III) salts nor $\mathrm{CF}_{3} \mathrm{CO}_{2} \mathrm{H}$ induce changes in the $\mathrm{UV} /$ vis absorption and Raman spectra of $\mathbf{1}$, although they provide sufficient Brønsted acidity to facilitate reduction of $\mathbf{1}$ by $\mathrm{H}_{2} \mathrm{O}_{2}$, as observed with carboxylic acids earlier. ${ }^{35,41}$ Indeed, there is no reason that the $\mathrm{p} K_{\mathrm{a}}$ of $\mathrm{Sc}\left(\mathrm{H}_{2} \mathrm{O}\right)_{x}$ species formed by hydrolysis should be lower than that of $\mathrm{TfOH}$ and hence the species responsible for protonation of 1 cannot be defined. It is of note, however, that cyclic voltammetry with $\mathrm{TfOH}$ is nearly identical to that with $\mathrm{Sc}(\mathrm{OTf})_{3}$. Hence, although we have characterized Brønsted acidity in the present study as being due to the formation of $\mathrm{TfOH}$ in situ, in reality the nature of the species that protonates $\mathbf{1}$ to form $\mathrm{Hi}^{+}$is ill-defined. Ultimately, the actual Brønsted acid responsible is of little concern in this case, but rather the effects observed are due to Brønsted rather than Lewis acidity. A point that is certain is that once water is added in molar excess, e.g., with $\mathrm{H}_{2} \mathrm{O}_{2}$, or formed by side reactions, the hydronium ion is the Brønsted acid involved. Notably the hydronium ion is a much weaker acid than $\mathrm{H1}^{+}$, and its addition, as shown above, results in a recovery of the original spectral features of $\mathbf{1}$. Nevertheless, the equilibrium position is sufficient (see cyclic voltammetry) to provide enough $\mathrm{H}^{+}$in solution for $\mathrm{H}_{2} \mathrm{O}_{2}$ to be able to initiate reduction. The initial reduction triggers an autocatalytic transformation of $\mathbf{1}$ into species in lower oxidation states as shown earlier. ${ }^{35,41}$

\section{CONCLUSION}

In summary, we have shown here that Lewis acidic metal triflates undergo rapid hydrolysis to generate strong Brønsted acids in acetonitrile under the conditions used for catalytic oxidations with $\mathrm{H}_{2} \mathrm{O}_{2}$. Indeed, even in anhydrous acetonitrile, residual water (ca. 0.5 to $3 \mathrm{mM} \mathrm{H}_{2} \mathrm{O}$ ) and water of crystallization ( 1 molecule per 1) can be sufficient for hydrolysis of the Lewis acid $\left(\mathrm{Sc}(\mathrm{OTf})_{3}\right)$. In the case of oxidation of alkenes with $\mathrm{H}_{2} \mathrm{O}_{2}$ and $\mathbf{1}$, the hydrolysis occurs well before the onset of substrate conversion. Hence, the postulated binding of Lewis acids to $\mathbf{1}$, or a putative reactive species, does not occur and the changes in spectral properties and enhancements in catalytic activity observed are due to Brønsted acids formed in situ. Indeed, Brønsted acids, i.e., carboxylic acids, were shown earlier to suppress disproportionation ${ }^{41}$ and allow for $\mathrm{H}_{2} \mathrm{O}_{2}$ to be used with complete efficiency in the oxidation of alkenes catalyzed by $\mathbf{1}$ with, e.g., 
$\mathrm{CCl}_{3} \mathrm{CO}_{2} \mathrm{H}$, with turnover numbers (TONs) exceeding 3000. 35,47

Although $\mathrm{Sc}^{3+}$-bound species have been observed crystallographically, ${ }^{32-34}$ the reactivity changes induced by such Lewis acids in solution are highly likely to be due to the release of Brønsted acids. The role of LAs as a source of Brønsted acids shown here impacts more broadly, for example, in the study of Lewis acid activation of iron and other metal catalysts. Beyond this, however, in recognizing the possibility to introduce strong Brønsted acids into reactions via $\mathrm{Sc}(\mathrm{OTf})_{3}$, the use of often difficult to handle strong acids directly can be circumvented.

\section{EXPERIMENTAL SECTION}

General Information. All reagents were of commercial grade (Sigma-Aldrich, TCI) and were used as received unless stated otherwise. $\mathrm{H}_{2} \mathrm{O}_{2}$ : Sigma-Aldrich, 50 wt $\% . \mathrm{H}_{2}{ }^{18} \mathrm{O}$ : Rotem Industries Ltd., 98\%. Anhydrous $\mathrm{CH}_{3} \mathrm{CN}$ (Sigma-Aldrich): 99.8\%, $<0.005 \%$ $\mathrm{H}_{2} \mathrm{O}(3 \mathrm{mM})$. The $1.5 \mathrm{M} \mathrm{Na}{ }^{18} \mathrm{OH}\left(\right.$ in $\mathrm{H}_{2}{ }^{18} \mathrm{O}$ ) was prepared by adding a piece of $\mathrm{Na}$ metal $(33 \mathrm{mg}, 0.29 \mathrm{mmol})$ to $1.0 \mathrm{~mL}$ of $\mathrm{H}_{2}{ }^{18} \mathrm{O}$. The mixture of $1 \mathrm{M} \mathrm{H}_{2} \mathrm{O}_{2}$ and $1.5 \mathrm{M} \mathrm{Na}^{18} \mathrm{OH}$ in $\mathrm{H}_{2}{ }^{18} \mathrm{O}$ was prepared by mixing a solution of $50 \mathrm{wt} \% \mathrm{H}_{2} \mathrm{O}_{2}(13 \mu \mathrm{L})$ and $\mathrm{H}_{2}{ }^{18} \mathrm{O}(250 \mu \mathrm{L})$ with the previously prepared $1.5 \mathrm{M} \mathrm{Na}^{18} \mathrm{OH}$ (aq.; $\left.200 \mu \mathrm{L}\right)$. $\left[\mathrm{Mn}_{2}(\mu\right.$ $\left.\mathrm{O})_{3}(\text { tmtacn })_{2}\right]\left(\mathrm{PF}_{6}\right)_{2} \cdot \mathrm{H}_{2} \mathrm{O}$ (1) was generously supplied by Catexel Ltd., and it was analyzed by elemental analysis (calcd for $\mathrm{Mn}_{2} \mathrm{C}_{18} \mathrm{H}_{44} \mathrm{~N}_{6} \mathrm{O}_{4} \mathrm{P}_{2} \mathrm{~F}_{12}$ ): C, 26.82\% (26.74\%); H, 5.39\% (5.49\%); $\mathrm{N}, 10.40 \%(10.40 \%)$.

Synthesis of ${ }^{18} \mathrm{O}-1$. The synthesis of $\left[\mathrm{Mn}_{2}\left(\mu-{ }^{18} \mathrm{O}\right)_{3}(\operatorname{tmtacn})_{2}\right]-$ $\left(\mathrm{PF}_{6}\right)_{2} \cdot \mathrm{H}_{2} \mathrm{O}\left({ }^{18} \mathrm{O}-1\right)$ was carried out by adaptation of the method described by Hage et al. ${ }^{53} \mathrm{~A}$ three-necked flask equipped with a small stirring egg was charged with tmtacn $(37 \mathrm{mg}, 0.22 \mathrm{mmol})$ and $1 \mathrm{~mL}$ of $\mathrm{H}_{2}{ }^{18} \mathrm{O}$. The mixture was purged with $\mathrm{N}_{2}$ and held under a $\mathrm{N}_{2}$ atmosphere. $\mathrm{MnSO}_{4} \cdot \mathrm{H}_{2} \mathrm{O}(38 \mathrm{mg}, 0.22 \mathrm{mmol})$ was added to the reaction mixture, after which the flask was cooled in an ice bath for 15 min. A premixed solution of $200 \mu \mathrm{L}$ of $1.5 \mathrm{M} \mathrm{Na}^{18} \mathrm{OH}$ and $263 \mu \mathrm{L}$ of $1 \mathrm{M} \mathrm{H}_{2} \mathrm{O}_{2}$ in $\mathrm{H}_{2}{ }^{18} \mathrm{O}$ was added slowly to the brown reaction mixture, upon which it turned black. The mixture was stirred on ice for $40 \mathrm{~min}$, during which it turned dark red, and was stirred at room temperature for another $45 \mathrm{~min}$. Then, $1 \mathrm{M} \mathrm{H}_{2} \mathrm{SO}_{4}$ in $\mathrm{H}_{2}{ }^{18} \mathrm{O}(150 \mu \mathrm{L})$ was added to the reaction mixture to reach $\mathrm{pH} 2$. The dark red reaction mixture was subsequently filtered by gravity over paper into a $10 \mathrm{~mL}$ flask. $\mathrm{KPF}_{6}$ (45 mg, $0.24 \mathrm{mmol}$ ) was added to the filtrate, upon which a precipitate formed immediately. The flask was kept in the fridge overnight to form microcrystalline needles, after which the solution was removed from the vial by Pasteur pipet, and the solid was washed with diethyl ether. The crystalline product was dried in the vial with gentle heating to remove residual water. The ${ }^{18} \mathrm{O}$-labeled product ${ }^{18} \mathrm{O}-1$ was characterized by Raman spectroscopy $\left(\lambda_{\text {exc }} 785 \mathrm{~nm}\right.$ (Figure S6)) and UV-vis absorption spectroscopy in $\mathrm{CH}_{3} \mathrm{CN}$.

Physical Measurements. Inductively Coupled Plasma Atomic absorption (ICP-AAS) spectra were recorded on a PerkinElmer Optima 7000 DV ICP. Electrochemical measurements were carried out on a model 760c Electrochemical Analyzer ( $\mathrm{CH}$ Instruments). Analyte concentrations were typically $1.0 \mathrm{mM}$ in anhydrous acetonitrile containing $0.1 \mathrm{M}$ tetrabutylammonium hexafluorophosphate $\left(\mathrm{TBAPF}_{6}\right)$, and a Teflon-shrouded glassy carbon (GC) working electrode ( $\mathrm{CH}$ Instruments), a Pt wire auxiliary electrode, and a saturated calomel electrode (SCE) reference electrode were employed unless stated otherwise. Cyclic voltammograms were obtained at scan rates between $0.1 \mathrm{~V} / \mathrm{s}$ and $1.0 \mathrm{~V} / \mathrm{s}$. UV/vis absorption spectra were recorded on an Analytik Jena Specord S300 or S600 spectrophotometer using $1 \mathrm{~cm}$ path length quartz cuvettes. Raman spectra at $\lambda_{\text {exc }}$ $785 \mathrm{~nm}$ were recorded using either a PerkinElmer Raman Station $400 \mathrm{~F}$ or RamanFlex or a home-built Raman spectrometer comprised of a Shamrock-300i spectrograph equipped with a iVac-A-DR-316BLDC-DD-RES CCD camera (Andor Technology) fiber coupled to an integrated Raman probe $(100 \mathrm{~mW}$ at source, Innovative Photonic Solutions). Raman spectra at $\lambda_{\text {exc }} 355 \mathrm{~nm}(10 \mathrm{~mW}$ at source, Cobolt Lasers) were recorded in a $180^{\circ}$ backscattering arrangement. Raman scattering was collected by a $2.5 \mathrm{~cm}$ diameter plano-convex lens $(f=$ $7.5 \mathrm{~cm}$ ), and the collimated Raman scattering was passed through an appropriate long pass edge filter (Semrock) after which it was focused by a second $2.5 \mathrm{~cm}$ diameter plano-convex lens $(f=15 \mathrm{~cm})$ into a Shamrock500i spectrograph (Andor Technology) with a $2399 \mathrm{~L} / \mathrm{mm}$ grating blazed at $300 \mathrm{~nm}$, and it was acquired with an iDus-420-BU2 CCD camera (Andor Technology). The spectral slit width was set to $12 \mu \mathrm{m}$. Raman spectra at $\lambda_{\text {exc }} 457 \mathrm{~nm}(50 \mathrm{~mW}$ at source, Cobolt Lasers) were recorded in a $180^{\circ}$ backscattering arrangement. Raman scattering was collected by a $2.5 \mathrm{~cm}$ diameter plano-convex lens $(\mathrm{f}=$ $7.5 \mathrm{~cm}$ ), and the collimated Raman scattering was passed through an appropriate long pass edge filter (Semrock) after which it was focused by a second $2.5 \mathrm{~cm}$ diameter plano-convex lens $(\mathrm{f}=7.5 \mathrm{~cm})$ into a Shamrock300i spectrograph (Andor Technology) with a $1200 \mathrm{~L} / \mathrm{mm}$ grating blazed at $500 \mathrm{~nm}$, and it was acquired with an iDus-420-BU CCD camera (Andor Technology).

Procedure Employed for Catalysis Studies. The Lewis acid ( $30 \mu \mathrm{L}$ of $100 \mathrm{mM}$ solution in $\mathrm{CH}_{3} \mathrm{CN}, 3 \mu \mathrm{mol}$ ) or Brønsted acid ( 30 $\mu \mathrm{L}$ of $300 \mathrm{mM}$ solution in $\mathrm{CH}_{3} \mathrm{CN}, 9 \mu \mathrm{mol}$ ) was added to $1.21 \mathrm{~mL}$ of a $1.24 \mathrm{mM}$ solution of $\mathbf{1}(1.5 \mu \mathrm{mol})$ in anhydrous $\mathrm{CH}_{3} \mathrm{CN}$, and this mixture was stirred for a certain standing time, after which styrene $(172 \mu \mathrm{L}, 1500 \mu \mathrm{mol})$ was added. The final concentrations in $1.5 \mathrm{~mL}$ reaction mixture: $1(1 \mathrm{mM})$, Lewis acid $(2 \mathrm{mM})$ or Brønsted acid $(6$ $\mathrm{mM})$, styrene $(1 \mathrm{M}), \mathrm{H}_{2} \mathrm{O}_{2}(1 \mathrm{M})$. Reaction progress was determined by Raman spectroscopy $\left(\lambda_{\text {exc }} 785 \mathrm{~nm}\right)$ with the initial time $(t=0)$ defined as the point of addition of $\mathrm{H}_{2} \mathrm{O}_{2}\left(85 \mu \mathrm{L}\right.$ of $50 \mathrm{wt} \%$ in $\mathrm{H}_{2} \mathrm{O}$, $1500 \mu \mathrm{mol})$. The conversion of styrene and consumption of $\mathrm{H}_{2} \mathrm{O}_{2}$ were monitored for approximately $30 \mathrm{~min}$. Epoxide formation was confirmed by ${ }^{1} \mathrm{H}$ NMR spectroscopy.

Caution! Complete disproportionation of $\mathrm{H}_{2} \mathrm{O}_{2}$ to oxygen and water can occur and hence the reactions should not be carried out in sealed vessels.

Note: Comparison of reaction progress data obtained in the present study with that in previous reports by Nodzewska and Watkinson showed the same reaction time $(3-4 \mathrm{~min}) .^{30} \mathrm{Lv}$ et al., ${ }^{31}$ however, applied general reaction conditions to each tested substrate, and therefore a reaction time of $2 \mathrm{~h}$ was reported for styrene. It is of note that in the aforementioned studies $0.1 \mathrm{M}$ styrene was used, in contrast to the present study with $1 \mathrm{M}$ and hence the effect of standing time would not have manifested itself in a difference in conversion in those studies.

ICP analysis confirms that the white precipitate formed during catalysis contained $10-16$ wt $\%$ of Mn and 5-20 wt \% of Sc in the form of insoluble salts. The insolubility and \%metal content is consistent with the anion being acetate. The FTIR spectrum indicates that the counterion is an organic compound which is affected by deuteration of the solvent ( $d_{3}$-acetonitrile) but does not contain a nitrile group (Figure S17). This precipitate is formed in the absence of substrate, and a preciptate is formed in the absence of the manganese complex also. Hence although the organic component could be due to a degradation product of the tmtacn ligand; more probably, hydrolysis of acetonitrile is responsible since the spectrum is solvent deuteration dependent. Comparison of these spectra with those of commercially available, and relatively anhydrous, scandium and manganese acetates is hampered by the effect of water (hydration state) on the spectrum, but the spectrum of the precipitate is close to that of $\mathrm{NaOAc}$ (Figure S18).

\section{ASSOCIATED CONTENT}

\section{Supporting Information}

The Supporting Information is available free of charge on the ACS Publications website at DOI: 10.1021/acs.inorgchem.9b02737.

Additional spectroscopic and electrochemical data (PDF) 


\section{AUTHOR INFORMATION}

\section{Corresponding Authors}

*E-mail: gmaja@chem.bg.ac.rs.

*E-mail: w.r.browne@rug.nl.

\section{ORCID $\odot$}

Marcel Swart: 0000-0002-8174-8488

Maja Gruden: 0000-0002-0746-5754

Wesley R. Browne: 0000-0001-5063-6961

\section{Present Address}

$\triangle$ Center for Chemistry, ICTM, University of Belgrade, Njegoševa 12, 11001 Belgrade, Serbia

\section{Notes}

The authors declare no competing financial interest.

\section{ACKNOWLEDGMENTS}

The COST association action CM1305 ECOSTBio (STSM grant 34080), the European Research Council (ERC 279549, W.R.B.), MINECO (CTQ2017-87392-P, M.S.), GenCat (2014SGR1202, M.S.), FEDER (UNGI10-4E-801, M.S.), the Chinese Scholarship Council (CSC), and The Netherlands Ministry of Education, Culture and Science (Gravity Program 024.001.035) are acknowledged for financial support. The Peregrine high performance computing cluster of the University of Groningen is acknowledged for computational resources.

\section{REFERENCES}

(1) Umena, Y.; Kawakami, K.; Shen, J. R.; Kamiya, N. Crystal

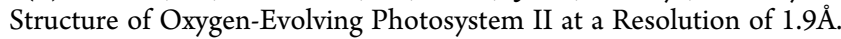
Nature 2011, 473 (7345), 55-60.

(2) Yano, J.; Yachandra, V. Mn4Ca Cluster in Photosynthesis: Where and How Water Is Oxidized to Dioxygen. Chem. Rev. 2014, 114 (8), 4175-4205.

(3) Kanady, J. S.; Tsui, E. Y.; Day, M. W.; Agapie, T. A Synthetic Model of the Mn3Ca Subsite of the Oxygen-Evolving Complex in Photosystem II. Science (Washington, DC, U. S.) 2011, 333 (6043), 733-736.

(4) Tsui, E. Y.; Agapie, T. Reduction Potentials of Heterometallic Manganese-Oxido Cubane Complexes Modulated by Redox-Inactive Metals. Proc. Natl. Acad. Sci. U. S. A. 2013, 110 (25), 10084-10088.

(5) Tsui, E. Y.; Tran, R.; Yano, J.; Agapie, T. Redox-Inactive Metals Modulate the Reduction Potential in Heterometallic ManganeseOxido Clusters. Nat. Chem. 2013, 5 (4), 293-299.

(6) Morimoto, Y.; Kotani, H.; Park, J.; Lee, Y.-M.; Nam, W.; Fukuzumi, S. Metal Ion-Coupled Electron Transfer of a Nonheme Oxoiron(IV) Complex: Remarkable Enhancement of ElectronTransfer Rates by Sc3+. J. Am. Chem. Soc. 2011, 133 (3), 403-405.

(7) Park, J.; Morimoto, Y.; Lee, Y.-M.; You, Y.; Nam, W.; Fukuzumi, S. Scandium Ion-Enhanced Oxidative Dimerization and N-Demethylation of N,N-Dimethylanilines by a Non-Heme Iron(IV)-Oxo Complex. Inorg. Chem. 2011, 50 (22), 11612-11622.

(8) Park, J.; Morimoto, Y.; Lee, Y.-M.; Nam, W.; Fukuzumi, S. Metal Ion Effect on the Switch of Mechanism from Direct Oxygen Transfer to Metal Ion-Coupled Electron Transfer in the Sulfoxidation of Thioanisoles by a Non-Heme Iron(IV)-Oxo Complex. J. Am. Chem. Soc. 2011, 133 (14), 5236-5239.

(9) Morimoto, Y.; Park, J.; Suenobu, T.; Lee, Y.-M.; Nam, W.; Fukuzumi, S. Mechanistic Borderline of One-Step Hydrogen Atom Transfer versus Stepwise Sc3+-Coupled Electron Transfer from Benzyl Alcohol Derivatives to a Non-Heme Iron(IV)-Oxo Complex. Inorg. Chem. 2012, 51 (18), 10025-10036.

(10) Bang, S.; Lee, Y.-M.; Hong, S.; Cho, K.-B.; Nishida, Y.; Seo, M. S.; Sarangi, R.; Fukuzumi, S.; Nam, W. Redox-Inactive Metal Ions Modulate the Reactivity and Oxygen Release of Mononuclear Non-
Haem Iron(III)-Peroxo Complexes. Nat. Chem. 2014, 6 (10), 934940.

(11) Zhang, J.; Wang, Y.; Luo, N.; Chen, Z.; Wu, K.; Yin, G. Redox Inactive Metal Ion Triggered N-Dealkylation by an Iron Catalyst with Dioxygen Activation: A Lesson from Lipoxygenases. Dalt. Trans. 2015, 44 (21), 9847-9859.

(12) Prakash, J.; Que, L. Formation of the Syn Isomer of $[\mathrm{FeIV}(\mathrm{Oanti})(\mathrm{TMC})(\mathrm{NCMe})] 2+$ in the Reaction of Lewis Acids with the Side-on Bound Peroxo Ligand in $[\mathrm{FeIII}(\mathrm{H} 2-\mathrm{O} 2)(\mathrm{TMC})]+$. Chem. Commun. 2016, 52 (52), 8146-8148.

(13) Zhang, J.; Wei, W. J.; Lu, X.; Yang, H.; Chen, Z.; Liao, R. Z.; Yin, G. Nonredox Metal Ions Promoted Olefin Epoxidation by Iron(II) Complexes with $\mathrm{H} 2 \mathrm{O} 2$ : DFT Calculations Reveal Multiple Channels for Oxygen Transfer. Inorg. Chem. 2017, 56 (24), 1513815149 .

(14) Kal, S.; Draksharapu, A.; Que, L. Sc3+ (or HClO4) Activation of a Nonheme FeIII-OOH Intermediate for the Rapid Hydroxylation of Cyclohexane and Benzene. J. Am. Chem. Soc. 2018, 140 (17), $5798-5804$.

(15) Kal, S.; Que, L. Activation of a Non-Heme FelII-OOH by a Second FeIII to Hydroxylate Strong $\mathrm{C}-\mathrm{H}$ Bonds: Possible Implications for Soluble Methane Monooxygenase. Angew. Chem., Int. Ed. 2019, 58 (25), 8484-8488.

(16) Park, Y. J.; Ziller, J. W.; Borovik, A. S. The Effects of RedoxInactive Metal Ions on the Activation of Dioxygen: Isolation and Characterization of a Heterobimetallic Complex Containing a MnIII( $\mu$-OH)-CaII Core. J. Am. Chem. Soc. 2011, 133 (24), 9258-9261.

(17) Leeladee, P.; Baglia, R. A.; Prokop, K. A.; Latifi, R.; De Visser, S. P.; Goldberg, D. P. Valence Tautomerism in a High-Valent Manganese-Oxo Porphyrinoid Complex Induced by a Lewis Acid. J. Am. Chem. Soc. 2012, 134 (25), 10397-10400.

(18) Baglia, R. A.; Krest, C. M.; Yang, T.; Leeladee, P.; Goldberg, D. P. High-Valent Manganese-Oxo Valence Tautomers and the Influence of Lewis/Brönsted Acids on C-H Bond Cleavage. Inorg. Chem. 2016, 55 (20), 10800-10809.

(19) Choe, C.; Lv, Z.; Wu, Y.; Chen, Z.; Sun, T.; Wang, H.; Li, G.; Yin, G. Promoting a Non-Heme Manganese Complex Catalyzed Oxygen Transfer Reaction by Both Lewis Acid and Brønsted Acid: Similarities and Distinctions. Mol. Catal. 2017, 438, 230-238.

(20) Sharma, N.; Jung, J.; Ohkubo, K.; Lee, Y.-M.; El-Khouly, M. E.; Nam, W.; Fukuzumi, S. Long-Lived Photoexcited State of a Mn(IV)Oxo Complex Binding Scandium Ions That Is Capable of Hydroxylating Benzene. J. Am. Chem. Soc. 2018, 140 (27), 84058409.

(21) Sankaralingam, M.; Lee, Y.-M.; Pineda-Galvan, Y.; Karmalkar, D. G.; Seo, M. S.; Jeon, S. H.; Pushkar, Y.; Fukuzumi, S.; Nam, W. Redox Reactivity of a Mononuclear Manganese-Oxo Complex Binding Calcium Ion and Other Redox-Inactive Metal Ions. J. Am. Chem. Soc. 2019, 141 (3), 1324-1336.

(22) Yoon, H.; Lee, Y.-M.; Wu, X.; Cho, K.-B.; Sarangi, R.; Nam, W.; Fukuzumi, S. Enhanced Electron-Transfer Reactivity of Nonheme Manganese(IV)-Oxo Complexes by Binding Scandium Ions. J. Am. Chem. Soc. 2013, 135 (24), 9186-9194.

(23) Chen, J.; Lee, Y.-M.; Davis, K. M.; Wu, X.; Seo, M. S.; Cho, K.B.; Yoon, H.; Park, Y. J.; Fukuzumi, S.; Pushkar, Y. N.; et al. A Mononuclear Non-Heme Manganese(IV)-Oxo Complex Binding Redox-Inactive Metal Ions. J. Am. Chem. Soc. 2013, 135 (17), 63886391.

(24) Dong, L.; Wang, Y.; Lv, Y.; Chen, Z.; Mei, F.; Xiong, H.; Yin, G. Lewis-Acid-Promoted Stoichiometric and Catalytic Oxidations by Manganese Complexes Having Cross-Bridged Cyclam Ligand: A Comprehensive Study. Inorg. Chem. 2013, 52 (9), 5418-5427.

(25) Zhang, Z.; Coats, K. L.; Chen, Z.; Hubin, T. J.; Yin, G. Influence of Calcium(II) and Chloride on the Oxidative Reactivity of a Manganese(II) Complex of a Cross-Bridged Cyclen Ligand. Inorg. Chem. 2014, 53 (22), 11937-11947.

(26) Choe, C.; Yang, L.; Lv, Z.; Mo, W.; Chen, Z.; Li, G.; Yin, G. Redox-Inactive Metal Ions Promoted the Catalytic Reactivity of Non- 
Heme Manganese Complexes towards Oxygen Atom Transfer. Dalt. Trans. 2015, 44 (19), 9182-9192.

(27) Chen, Z.; Yang, L.; Choe, C.; Lv, Z.; Yin, G. Non-Redox Metal Ion Promoted Oxygen Transfer by a Non-Heme Manganese Catalyst. Chem. Commun. 2015, 51 (10), 1874-1877.

(28) Kim, S.; Cho, K.-B.; Lee, Y.-M.; Chen, J.; Fukuzumi, S.; Nam, W. Factors Controlling the Chemoselectivity in the Oxidation of Olefins by Nonheme Manganese(IV)-Oxo Complexes. J. Am. Chem. Soc. 2016, 138 (33), 10654-10663.

(29) Hong, S.; Lee, Y.-M.; Sankaralingam, M.; Vardhaman, A. K.; Park, Y. J.; Cho, K.-B.; Ogura, T.; Sarangi, R.; Fukuzumi, S.; Nam, W. A Manganese(V)-Oxo Complex: Synthesis by Dioxygen Activation and Enhancement of Its Oxidizing Power by Binding Scandium Ion. J. Am. Chem. Soc. 2016, 138 (27), 8523-8532.

(30) Nodzewska, A.; Watkinson, M. Remarkable Increase in the Rate of the Catalytic Epoxidation of Electron Deficient Styrenes through the Addition of $\mathrm{Sc}(\mathrm{OTf}) 3$ to the MnTMTACN Catalyst. Chem. Commun. 2018, 54 (12), 1461-1464.

(31) Lv, Z.; Choe, C.; Wu, Y.; Wang, H.; Chen, Z.; Li, G.; Yin, G. Non-Redox Metal Ions Accelerated Oxygen Atom Transfer by MnMe3tacn Complex with $\mathrm{H} 2 \mathrm{O} 2$ as Oxygen Resource. Mol. Catal. 2018, 448, 46-52.

(32) Fukuzumi, S.; Morimoto, Y.; Kotani, H.; Naumov, P.; Lee, Y.M.; Nam, W. Crystal Structure of a Metal Ion-Bound Oxoiron(IV) Complex and Implications for Biological Electron Transfer. Nat. Chem. 2010, 2 (9), 756-759.

(33) Swart, M. A Change in the Oxidation State of Iron: Scandium Is Not Innocent. Chem. Commun. 2013, 49 (59), 6650-6652.

(34) Prakash, J.; Rohde, G. T.; Meier, K. K.; Jasniewski, A. J.; Van Heuvelen, K. M.; Münck, E.; Que, L. Spectroscopic Identification of an FeIII Center, Not FeIV, in the Crystalline $\mathrm{Sc}-\mathrm{O}-\mathrm{Fe}$ Adduct Derived from $[\mathrm{FeIV}(\mathrm{O})(\mathrm{TMC})] 2+$. J. Am. Chem. Soc. 2015, 137 (10), 3478-3481.

(35) de Boer, J. W.; Browne, W. R.; Brinksma, J.; Alsters, P. L.; Hage, R.; Feringa, B. L. Mechanism of Cis-Dihydroxylation and Epoxidation of Alkenes by Highly $\mathrm{H} 2 \mathrm{O} 2$ Efficient Dinuclear Manganese Catalysts. Inorg. Chem. 2007, 46 (16), 6353-6372.

(36) Krieble, V. K.; Noll, C. I. The Hydrolysis of Nitriles with Acids. J. Am. Chem. Soc. 1939, 61 (3), 560-563.

(37) Lei, X. R.; Gong, C.; Zhang, Y. L.; Xu, X. Influence of the Acetamide from Acetonitrile Hydrolysis in Acid-Contained Mobile Phase on the Ultraviolet Detection in High Performance Liquid Chromatography. Chromatographia 2016, 79 (19-20), 1257-1262.

(38) Kobayashi, S.; Nagayama, S.; Busujima, T. Lewis Acid Catalysts Stable in Water. Correlation between Catalytic Activity in Water and Hydrolysis Constants and Exchange Rate Constants for Substitution of Inner-Sphere Water Ligands. J. Am. Chem. Soc. 1998, 120 (32), $8287-8288$.

(39) Wieghardt, K.; Bossek, U.; Nuber, B.; Weiss, J.; Bonvoisin, J.; Corbella, M.; Vitols, S. E.; Girerd, J. J. Synthesis, Crystal Structures, Reactivity, and Magnetochemistry of a Series of Binuclear Complexes of Manganese(II), -(III), and -(IV) of Biological Relevance. The Crystal Structure of $\left[\mathrm{L}^{\prime} \mathrm{MnIV}(\mu-\mathrm{O}) 3 \mathrm{MnIVL}^{\prime}\right](\mathrm{PF} 6) 2 . \mathrm{H} 2 \mathrm{O}$ Containing an Unprecedented Short Mn. J. Am. Chem. Soc. 1988, 110 (22), 7398-7411.

(40) Hage, R.; Krijnen, B.; Warnaar, J. B.; Hartl, F.; Stufkens, D. J.; Snoeck, T. L. Proton-Coupled Electron-Transfer Reactions in $\left[\operatorname{MnIV} 2(\mu-\mathrm{O}) 3 \mathrm{~L}^{\prime} 2\right] 2+\left(\mathrm{L}^{\prime}=1,4,7-\right.$ Trimethyl-1,4,7-Triazacyclononane). Inorg. Chem. 1995, 34 (20), 4973-4978.

(41) Angelone, D.; Abdolahzadeh, S.; de Boer, J. W.; Browne, W. R. Mechanistic Links in the In-Situ Formation of Dinuclear Manganese Catalysts, $\mathrm{H} 2 \mathrm{O} 2$ Disproportionation, and Alkene Oxidation. Eur. J. Inorg. Chem. 2015, 2015 (21), 3532-3542.

(42) Chin Quee-Smith, V.; DelPizzo, L.; Jureller, S. H.; Kerschner, J. L.; Hage, R. Synthesis, Structure, and Characterization of a Novel Manganese(IV) Monomer, $[\mathrm{MnIV}(\mathrm{Me} 3 \mathrm{TACN})(\mathrm{OMe}) 3](\mathrm{PF} 6)$ (Me3TACN = N,N ',N "-Trimethyl-1,4,7-Triazacyclononane), and Its Activity toward Olefin Oxidation with Hydrogen Peroxide. Inorg. Chem. 1996, 35 (22), 6461-6465.
(43) Padamati, S. K.; Angelone, D.; Draksharapu, A.; Primi, G.; Martin, D. J.; Tromp, M.; Swart, M.; Browne, W. R. Transient Formation and Reactivity of a High-Valent Nickel(IV) Oxido Complex. J. Am. Chem. Soc. 2017, 139 (25), 8718-8724.

(44) Niemann, A.; Bossek, U.; Wieghardt, K.; Butzlaff, C.; Trautwein, A. X.; Nuber, B. A New Structure-Magnetism Relationship for Face-Sharing Transition-Metal Complexes with D3-D3 Electronic Configuration. Angew. Chem., Int. Ed. Engl. 1992, 31 (3), $311-313$

(45) Brown, P. L.; Ellis, J.; Sylva, R. N. The Hydrolysis of Metal Ions. Part 6. Scandium(III). J. Chem. Soc., Dalton Trans. 1983, 35-36.

(46) Miao, C.; Wang, B.; Wang, Y.; Xia, C.; Lee, Y.-M. M.; Nam, W.; Sun, W. Proton-Promoted and Anion-Enhanced Epoxidation of Olefins by Hydrogen Peroxide in the Presence of Nonheme Manganese Catalysts. J. Am. Chem. Soc. 2016, 138 (3), 936-943.

(47) de Boer, J. W.; Brinksma, J.; Browne, W. R.; Meetsma, A.; Alsters, P. L.; Hage, R.; Feringa, B. L. Cis-Dihydroxylation and Epoxidation of Alkenes by [Mn2O(RCO2)2(Tmtacn)2]: Tailoring the Selectivity of a Highly H2O2-Efficient Catalyst. J. Am. Chem. Soc. 2005, 127 (22), 7990-7991.

(48) Dang, T. T.; Boeck, F.; Hintermann, L. Hidden Brønsted Acid Catalysis: Pathways of Accidental or Deliberate Generation of Triflic Acid from Metal Triflates. J. Org. Chem. 2011, 76 (22), 9353-9361.

(49) Sletten, E. T.; Tu, Y. J.; Schlegel, H. B.; Nguyen, H. M. Are Brønsted Acids the True Promoter of Metal-Triflate-Catalyzed Glycosylations? A Mechanistic Probe into 1,2- Cis-Aminoglycoside Formation by Nickel Triflate. ACS Catal. 2019, 9 (3), 2110-2123.

(50) Chen, J.; Goforth, S. K.; McKeown, B. A.; Gunnoe, T. B. Brønsted Acid-Catalysed Intramolecular Hydroamination of Unactivated Alkenes: Metal Triflates as an in Situ Source of Triflic Acid. Dalt. Trans. 2017, 46 (9), 2884-2891.

(51) Dumeunier, R.; Markó, I. E. On the Role of Triflic Acid in the Metal Triflate-Catalysed Acylation of Alcohols. Tetrahedron Lett. 2004, 45 (4), 825-829.

(52) Wabnitz, T. C.; Yu, J.-Q.; Spencer, J. B. Evidence That Protons Can Be the Active Catalysts in Lewis Acid Mediated Hetero-Michael Addition Reactions. Chem. - Eur. J. 2004, 10 (2), 484-493.

(53) Kemp, R. W.; Hage, R.; Zhao, W.; Zhang, J.; Jiang, Y.; Xie, H. Catalysts. WO2013/033864, 2009. 